of prolapse into the vauinal canal, resembling a soft small vaginal portion of the cervix uteri. The peritoneal edges of the divided broad ligaments are brought together by a line of sutures $d d d$, so as to protect the peritoneal cavity from the entrance of anything upwards from the vagina.

I cannot take up more of your tine with this subject, but I do say that should it, in some cases (no doubt they would be rare), be dęemed desirable and justifiable to remove an entire uterus affected by cancer, this appears to me to be the best way hitherto described of doing it with a reasonable hope of success.

The hour is nearly complete, but I cannot conclule the very hasty and imperfect review of the subject of abdominal tumours, which I have been able to condense in six lectures, the operation now accepted as the only effectual means of relief in cases of ovarian tumours especially, and of the results which have been obtained in alleviating distress and prolonging valuable life, without some reference to the man who is justly looked upon as the "father of ovarintomy". Me Dowell was wise, practical, and prophetic. IIe carefully studied the subject which filled his mind; did with an enviable success what his opportunities permitted; and looked with an anxious eye on the prospect opening up to his successors. We, more happy in our opportunities, have entered into full possession of what to him was little more than a promised land ; and, speaking personally, I feel it my greatest happiness to have been able, chiefly through the encouragement of professional brethren (which at one time I had little reason to anticipate), to reach the point at which McDowell aimed. I have not only attained the amount of operative success which he gave as the standard; I have not only the almost daily gratification of seeing some living and enduring evidence $v$, that my labours have not been in vain; but $I$ have, for the rest of my days, the satisfaction of knowing that my example has em. boldened others, and will be the means of still fur ther exiending to human suffering the cors slatory assurance of the prospect of relief and ensuring the certainty of its realisation by the many skilful hands which are now betaking themselves to the work. This is a lot which falls to but few innovators. It is not given to every one to see the fruit of his labours; but the surest way of gaining that end is by studying the words and following the counsels of wisdom. The wish to do well what others have done is not all that is wanted. Step by step their course must be followed, difficult still, but somewhat easier from the result of experience; and while I content myself with a warning to aspirants that a fancied inspiration will not alone carry them on to success, I feel that I cannot quit them and the subject letter than by repeating the words of McDowell, who though better known in the open rugged field of practice than in the paths of literature, was a man of broad and elevated views, and thus expressed the advanced opinions he ha already formed respecting the operation he had inaugurated after years of patient waiting and zealous preparation. He strove to make ovariotomy a boon to humanity. He had reason to believe it had proved so, but he foresaw the dangers of its abuse from rash and indiscriminate rivalry amongst his followers. Listen to his own words. "I think my description of the mode of operating, and of the anatomy of the parts concerned, clear enough to enable any good anatumist, possessing the judgment requisite for a surgeon, to operate with safety. I hope no operator of any other description may ever attempt it. It is my most ardent wish that this operation may remain to the mechanical surge (n for ever incomprehensible. Such have been the bane of the science, intruding themselves into the ranks of the profession with no othcr qualification but boldness in undertaking, ignorance of their responsibility, and indiff=rence to the lives of their patients; proceeding ac cording to the special dictate of some author as mechanical as them. selves, they cut and tear with fearless indifference, utterly incapable of exercising any judgment of their own in cases of emergency, and some. times without possessing the slightest knowledge of the anatorny of the parts concerned. The preposterous and injurious attempts of such pretenders can seldiom fail to prove destructive to the patients and disgraceful to the science. It is by such this noble science has been degraded, in the minds of many, to the rank of an art."

In conclusion, allow me to read a sentence or tiwo from one of those able reviews which make one regret that the day of the medical quarterlies is passed. (British and Foreign Medical Reviczi, April 1873.) "All honour to McDowell of Kentucky, who, to use the words of Hufeland, "looked upon his profession as a high and holy office, who exercised it purely, not for his own advancement, not for his own honour, but for the glory of God and the good of his neighbour, and who, long since called to give an account of it, is no doubt reaping the reward of his faithful stewardship'."

\section{CLINICAL LECTURE on}

\section{A CALCUlus LARGELY COMPOSED OF INDIGO.}

\author{
Ditiairal at St. Thomas's Hospital.
}

DY W I L I I A II M. O R D, M. D.Lond., F.R. C.P., Pinysician to the II ospital.

Tile preparation I now place before you contains two calculi ; the upper one from the right, the lower one from the left, kidney of one and the same patient. They wcre sent to mc, togeiher with the kidneys containing them, by my friend Dr. Bloxam of Mount Street, the parts having been removed by him from the body of a patient who had died of malignant disease.

The left kidney had been reluced to the state of a lobulated cyst by a large medullary sareoma. The ureter was obliterated; and this, no doubt, had led to the destruction of the kidney. In the cystic kidney was the branched calculus (lower specimin) here shown. The right kiciney was increased in size, but was healthy. In its pelvis lay the flat blackish cake (upper specimen) here shown. This, at the time of its removal, was noticed to make a blackish-blue mark on paper, and I show you now the paper in which it was sent to me-the various parts were each carefully packed and labelled-marked on the outside "from the right kidney", and within showi:ng blue-black blotches, where it had been pressed against the calculus.

I may say at once that, when I first handled the calculus, which is an oval disc, seven-eighths of an inch longr, nine-sixtcenths broad, and one-tenth thick, in shape and lnok not unlike one of the fruit-lozenges used as vehicles for throat medicines, I looked upon it as probably a mixture of blood ard phosphates. In colour, it is partly dark-brown, in parts black; the blick surface finely granular, but taking a poiish when rubbed with the thumb-nail. It is of the consistence of a very fine hard chalk or slate. Although the surface looks friable, the sub. stance is very firm, and the section is polished by the saw as it traverses the interior with some difficulty. The hard central part is blue-grey, and does not ma:k paper. There is no concentric lamination or nucleus.

EXANination. - I. When a portion was hea ed on platinum foilthe first step in examination-it gave off an offensive $m_{i}$ oke, partly like that of burning fibrin, but with a character of its own besides, which I did not recognise at the time, but, on subsequent comparison, found to be idertical with the character of the oduur of burning indigo. $A$ considerable white ash was left, which consisterl of phosphate of lime, with a little masnesia.

II. A small portion being powdered and examined in water, under the microscope, was found to be partly brown and transparcit, without organic structure, and with transparent crystalline malters imbedded ; partly black and opaque. But here and there the black and the brown werc mingled; little tufts of dark matter being scalterted among the brown. The smallest looked blue in colour, and the same colour was observed at some puints on the marcin of black pigmented fragments.

111. After the action of hydrochloric acid, a large mass of friable stuff remained insoluble, and, uncier the microscope, was found to con. sist mainly of blue pigment, with here and there a coppery lustre. These observations were repeated several times with great caution on specimens taken from various parts of the calculus. And now the idea of indigo began to take shape.

1v. Accordingly, abuut a grain of well-powdered ca'culus stuff was put in a dry te-t-tube, and the flame of a spirit lamp was slowly applicd. $A$ purple vapour, very like that of iodine, was disengaged and filled the tube as high as three fourtis of an inch from the botiom. On removal of the heat, the vapour at unce condensed on the tube and on the powder from which it had been disengaged. The deposit on the tube is here shown. It is composed of blue crystals-elongated sixsided tablets, variously grouped in crosses and stars. 'The vapour, in colour and behaviour, is exactly like that of indigo which I now exhibit to you. The crystals now sublimed are, as seen under the microscope, exactly like those from the calculus.

For more ready comparison, I have prepared two slides of crystals for the microscope, which I now show you. They were made thus. Some powder, of the calculus in one case, of cummon commercial indigo in the other, was placed on a sheet of clean platinum foil. Round it was placed a glass ring, such as microscope cells are made with; and 
on the ring was splaced a glass slip, so that the middle of the alip covered the cell. Heat being applied, a sublimate collectedi on: the slip, and was mounted in glycerine. The, two preparations are here exhibited side. by side under the microscope, and 1 think you will have no doubt of the identity of the two substances. Bath.consist of crystals: of an intense blue colour, mixed with granules of the same colour. The crystals are long tables, sometimes hexagonal, sometimes square or notehed, sometimes comb-like, at the ends.

$\mathrm{v}$. The preceding observation is alone. almost conclusive of the identity of the pismentary constituent of the calculus with indigo. But a further test was applied: A grain of the calculus was powdered fine, and then rubbed up with strong sulphuric acid. The mixture, after standing for a fortright, was of a deep-blue colour, and, after dilution and filtration, gave the beautiful blue solution here exhibited. I have to thank Dr. Thudichum for completing this preparation, and for many kind hints and susgestions. The solution, viewed through the spectroscope, gives a band in the yellow coinciding with the band in a similarly prepared solution of common indigo. This is the only. band, and it may be observed that the blue end of the spectrum is very brilliant. I exhibit at the same time a solution of sulphate of copper, which gives a band in the extreme red, and cuts off much b'ue; and also a solution of indigo in chloroform, prepared from the urine of a patient with enteric fever. The band in the yellow is very strongly marked. Here are also solutions of logwood and aniline-blue, which give very different spectra. This spectium reaction seems to me to be decisive, when taken in conjunction with the preceding, in proving that the substance is actually indigo-blue.

VI. The hæmin test for bluod was applied. Some of the powdered calculus was heated with chloride of sodium and glacial acetic acid. It gave a blue solution, which, on evaporation, deposited the indigo in ctystals having a coppery lustre. A few hæinin crystals were found in the reddish-brown part of the calculus after the process.

Reviewing the examination, the conclusions to be arrived at are : that the calculus consists of a matrix of phosphate of lime and magnesia, with a little remains of blood.clot; that this matrix is everywhere in. terpenetrated by indigo-blue, with a little indigo-red; and that indigoblue has been deposited in large proportion as an incrustation.

Before attempting to explain the occurrence of indigo-blue in the caleulus, let us look for a moment at the possible relations of indigo as a constituent of urine. Indigo blue $\left(\mathrm{C}_{8} \mathrm{H}_{5} \mathrm{NO}\right)$, although a highly nitrogenised substance, is, as you all know, a product of the vegetable kingdom, being derived from the jyice of woad (Isatis tincturia) and from several kinds of Indigofera. It does not exist in the plant-juices as indigo-blue; but is produced in green or white solutions by a process of fermentation, during which carbonic acid is evolved and oxygen is absorbed.

Among many explanations by which the development of the blue pigment, under these circumstances, has been accounted for, that of Schunk is most generally received. According to Schunk, the various indigoferous juices contain a soluble culourless material, to which he has given the name of Indican $\left(\mathrm{C}_{23} \mathrm{H}_{31} \mathrm{NO}_{17}\right)$. This, under the influence of acids, takes up water, and breaks into indigo-blue and indiglucin, thus :

$$
\underset{\text { Indican. }}{\mathrm{C}_{26} \mathrm{H}_{31} \mathrm{NO}_{17}}+2 \mathrm{H}_{8} \mathrm{O}=\underset{\text { Indigo-blue. }}{\mathrm{C}_{8} \mathrm{H}_{6} \mathrm{NO}}+\underset{\substack{\text { Indiglucin. } \\ \text { Ind }}}{\mathrm{C}_{6} \mathrm{H}_{10} \mathrm{O}_{8}}
$$

The same observer has obtained from urine a substance resembling indican, and believes that indigo-blue, when obtained from urine, is so obtained by the decomposition of indican. The indican of urine is a more stable compound than the indican of isatis or other vegetajles.

It must next be stated that indigo-blue has been shown by many observers to be formed in urine spontaneously, or by the aid of acids and oxygen. The substance called cyanourine by Braconnet was probably indigo. Prout, after speaking of Prussian-blue as a constituent of urine, relates a case in which indigo (at first supposed by him to be Prussian-blue) was deposited from the urine of a patient whenever he took a seidlitz-powder. The deposit appears to have been spontaneous, and was copious enough to allow a verification by way of sublimation Gubler, Hassall, Thudichum, Odling, George Harley, and many others, have made similar observations. Indigo-blue has also been found in the blood of animals, both herbivorous and carnivorous, and in the.blood of man and of the ox (Carter).

The occurrence of indigogenous material in urine may be explained in two principal ways. It may be due to the ingestion of indigogenous material, or to breaking down of nitrogenous material within the body. In animals, the quantity of indigo in the urine is certainly increased during feeding with indigo yielding plants. In man, this is not so well established. But in man, the use of carbolic acid and creasote is often followed by a blackening of the urine-due, in part at least, to indigo. Of this I shall have to speak on a future occasion; but I may say $2 t$ present that. Dr. Oulling has domonstrated the presence of, indigo in a case of this kind. That indigo maythane the second source is proved by the fact of its presence in the urine of animals fed on flesh only, and in the urine of starxing animals (Jaff')

The next question that arises is : F nom what constituents of the body can the indican be derived? Here, aggin, thore are two graups, of sub. stances which may yield it. First, it may, be a dexivative of blood. pigment; second, of albuminous bodies Dr. Hassally mone than twenty years ago, pointed out the general agreementin chemical composition between the colouring ; matter of urine, indiga, and bloodpigment. And Dr. George Harley has adduced good, evidence that the agreement between these three is not confiued to the proportions of the fuur elements $\mathrm{CHNO}$, but includes the presence of iron in much the same proportion througbout the three matters. The presence of leucin and of sugar has been asserted of the urines yielding indigo: the one being beld to support the idea of the breaking up of albuminous matters; the other of indican, or a substance like it. And this leads us to the second possible source.

Recent observations have shown great reason for believing that indigo-blue in urine is connected with the formation and subsequent oxydation of indol in the system. Indol (Baeyer) has the composition $\mathrm{C}_{8} \mathrm{H}_{7} \mathrm{~N}$. It may be prepared by acting on indigo-blue with nascent hydrogen, and is a volatile crystalline substance, soluble in water and alcohol, and having an offensive odour. It. may be also obtained by the decomposition of albuminous substances, is one of the results of the action of pancreatic juice on peptones, and is found in faces, which are supposed to owe much of their peculiar odour to it (Baeyer.) Its chemical nearness to leucin and tyrosin is in this respect of great interest. Jaffé and others have shown that the subcutaneous adminis. tration of indol is followed by great inerease of indigg in the utine of animals experimented on Pus, again, has, as you know, often a greenish or bluivh colour, due to the presence of a material sometimes called pyocyanine, but which is aot Improbably indigo. . Comparing these experimental abservations wish clinical observations of the observers before quoted, as well as with those of Senator and with some of my own, it may be inferred with much probability that several kinds of condition within the body will be capable of producing excess of indigo in the urine. Among these, $I$ include (I): defective gastric chemistry ; (II), intestinal disorder of chemical kind; (III), intestinal obstruction; (IV), diarihœe; (V). suppurations in any part of the body, but specially in the urinary tracts; $(\mathrm{VI})$, morbid prnoesses, involving degeneration or destruction of albuminous tissues or blood. In relation to these, it may be noted that in cholera, in intestinal obstructions, and in typhoid fever, the quantity of indigo yielded by urine is often very large. Gubler, Hassall, and Thudichum have demonstrated this in cholera. Jaffé has pointed it out in intestinal obstruction and in intestinal fever, and has argued with much reason that straying of indol is the cause. In illustration, we have here two urinesfrom different enteric fever patients, and one from a case of intestinal obstruction. I have not as yet tested them, but will now do so. To this from an enteric case I add an equal bulk of fuming hydrochloric acid, and stir the mixture. Very little chan 8 is produced. If this were left exposed to the air, such indigo as is present would, in process of time, be depasited. Bat we have a quicker method. I add a drop of strong solution of bypochlorite of lime, and at once a bluish darkening of the fluid is seen. Now, another drop and a litule stirring, and now the mixture is alnost opaque, with blue-black colour. Some chloroform is now poured in and well stirred. You see that it has become intensely blue, though still quite transparent. The indigo is dissolved in the chloroform and the solution, if diluted with more chloroform, gives, as you will see presently, the characteristic band in the yellow of the spectrum. This is an unusually vivid reaction, the colour ordinarily obtained being no more than a blue or a greenish-blue tinting, while this solution is almost as dark as blue ink. The other specimens yield, as you see, almost as strong a colour, and very happily illastrate the intestinal relation to which I wish to direct your attention. The indigo here exhibited on filter.paper was obtained for me last year by Dr. Charles, from the urine of a child having extensixe joint and bone suppura!ion.

In several cases, $I$ have observed that pyelitic urine is rich in indigo. The urine of a patient in Charity Ward is bere shown. He has calculous pyelitis, and you will observe what a brilliant blue follows the application of our tests; not nearly, however, so deep as in the other cases. The urine contains no pus at present, bat much macus.

As regards albuminous degeneration, I may remind you that $\mathrm{Dr}$. Warburton Begbie has found much indigo in the urine of persons suffering from lardaceous degeneration of the liver; and that, again, this condition has a special relation to long-continued suppuration. Speaking generally, it is probable that indigo, being yielded regularly by the urine, may have one regular source, to which, 
in pathological states, others may be added. We may be reminded that uric acid has almost certainly several sources, and more than one import. I cannot say at present that these observations go far to unravel the mystery of the presence of indigo in the calculus. Dr. Bloxam tells me that the patient took creasote, for some days before death, for vomiting ; and this may be one source. Dr. Thudichum's suggestion is, that the indigogenous material was found in the suppurating left kidney in the presence of an alkali, was absorbed thence, and carried in the alkaline blood to the healthy right kidney, and then deposited as indigo-blue on contact with acid urine. This is most ingenious and plausible. There is yet another possible source in the cachexia of the patient. To me the value of the calculus will not be in my being able to explain its formation as an isolated phenomenon, but in the impulse which it will give me to work at the meanings lying beneath the appearance of indigo in urine. On this subject, Mr. Seymour Taylor and I have already set to work, and I hope some day to tell you more than I know now.

The calculus from the left kidney may now be examined. It is, as you see, a long branched calculus, corresponding roughly to the form of the pelvis and infundibulum of the kidney. In the first place, it must be stated that it contains no indigo, or indigo-yielding material. Its composition is very different in different parts, and a short review will show you how a calculus may be made to tell its own history. The central part is very friable, and of a very faint pinkish-white colour. The constituents are phosphate of lime, a very little carbonate, and uric acid. The latter occurs in beautiful bunches of prisms, and is apparently combined with lime. The phosphate is in spherules of small size. The crust contains in some layers no uric acid at all. These are the outer-layers, and they are composed very largely of carbonate of lime. It is worthy of note that the carbonate of lime here fails to give one ordinary reaction. It does not effervesce with slightly diluted acetic acid, although the effervescence with hydrochloric acid is very active. This is probably due to the organic matter with which the carbonate is intimately mixed. The centre of the calculus is evidently an urinary product. But the presence of carbonate of lime in large proportion, and the absence of uric acid in the outer layers, makes it probable that these were deposited after the kidney had, by the occlusion of the ureter, been shut off from the bladder, and ultimately reduced to a cyst. There is generally reason to suppose that, in man, carbonate of lime is very rarely deposited from urine, being formed only in the glandular diver. ticula of the urinary tracts. In herbivora, however, this is not the case. The matrix of the calculus is structureless, and gives us no information.

\section{CASE OF GENERAL ATROPHY OF STOMACH, WITH ABSENCE OF ORGANIC DISEASE.}

By A. B. BRABAZON, M.D.,

Physician to the Mineral Water Hospital, Bath.

ON September $15^{\text {th }}$, 1877 , at 7 P.M., I was requested to visit a lady in my immediate neighbourhood, about whose present condition her friends had become suddenly alarmed. I immediately attended; and there was presented to my notice a lady whom I knew well personally, and whom for years I had seen almost daily in her usual walks and drives. I had not had an opportunity of seeing her for about six weeks before the present occasion, as she had been absent from home.

I was almost horrified to see the change which had taken place in her personal appearance and aspeet. When I had last seen her, she then presented the appearance of, I may say, "rude health": stout, but not inordinately so ; active in her habits, cheerful in her disposition her face almost ruddy with the glow of health; in fact, a " comely English matron". Now I saw a perfectly colourless face; a countenance worn and pinched; gums and lips blanched, and conjunctiva yellowish white. The extremities were cold; pulse 128, small and feeble; sounds of heart indistinct; first sound masked by anæmic bruit; respiration natural. She complained of no pain in any part of her body. There was a total absence of subjective symptoms. She complained only of an indescribable feeling of utter prostration and complete inability, or rather dislike, to the-slightest exertion.

I at once ordered her to bed and advised the usual restoratives; and, finding that my friend $\mathbf{M r}$. Biggs had been in attendance for some time, I advised that they should send for him as early as possible, and explained that, except in conjunction with him, I could not see the patient again.

According to the wishes of the lady's friends, we met on the following day, and I had the advantage of Mr. Biggs's previous experience of the case. As to medical history, there was really none. This lady was sixty-three years of age, and had gone to Clevedon, apparently in good health, for her usual summer sojourn. While there; she had an attack of diarrhoea-not an unusual occurrence with her; and her appetite declined. She complained of feeling weak and depressed, and her colour gradully disappeared. There was no apparent loss of flesh; no sickness; no pain anywhere complained of; no great thirst. The diarrhcea ceased very soon. Mr. Biggs saw her on her return home, and was struck by the change in her appearance. He carefully examined her, and found nothing to account for the change.

We made a most careful examination on this occasion. To be brief, there was not a single objective symptom of organic disease of head, chest, or abdomen. The subjective symptoms, with the exception of those already stated, were equally negative : no pain; no nausea; no oppressive thirst; no diarrhœa, or the reverse. The urinary secretion, carefully tested by Mr. Biggs, was perfectly normal in quantity and quality. The temperature was normal. It was certainly a puzzling case. The general aspect of the patient suggested the possibility of malignant disease. Her age suggested the possibility of cancer uteri; but inquiries negatived the idea. The only diagnosis we could arrive at was that assimilation and nutrition, as far as sanguification was concerned, were in almost complete abeyance. Time alone could possibly reveal the cause of these conditions. The prognosis was most unfavourable.

Matters went on thus for a week. There was no sign of improvement; strength was gradually decreasing. The patient gave the same answer day after day: "No pain whatever". I should mention that, with all this, there was no corresponding emaciation. As far as external appearances went, the body was well nourished.

Considering the peculiar nature of the case, its rare character, and the certain fatal termination, Mr. Biggs and I suggested to the friends the advisability of having a third and perfectly independent opinion, for their future satisfaction. This they agreed to, and accordingly on Saturday, September 29th, we met Dr. Goodridge in consultation. Dr. Goodridge examined the patient with all the attention to detail of symptoms, objective and subjective, for which he has acquired a deserved reputation. His opinion was that there was no evidence of organic disease, malignant or non-malignant; that there was serious interference with the processes of assimilation and nutrition, and consequently blood-making; and that the only cause of this condition which occurred to him was atrophy of the glandular apparatus of the stomach, as the case brought to his mind some similar case or cases recorded by Dr. Fenwick, in which such a condition existed. He fully concurred in a most unfavourable prognosis. The symptoms remained the same, if nothing but progressive weakness can be called a symptom; and the patient gradually became unconscious, and died on October $5^{\text {th }}$.

We were fortunate in being permitted to make a post mortem examination with certain restrictions. On October $6 \mathrm{th}, \mathrm{Mr}$. Biggs and I made an examination of the contents of the abdomen. We found the body fairly nourished; subcutaneous fat in abundance. The omentum also was well supplied with fat. The solid viscera were all normal as regarded size and position. The liver was healthy, but infiltrated with bile. There was a gall-stone in the neck of the gall-bladder. The spleen was natural in size and structure. The kidneys were small, but perfectly healthy; so also was the pancreas. The condition of the stomach attracted our particular attention. As a demonstrator and lecturer on anatomy for many years, I have seen and examined hundreds of stomachs. I have never seen so small a stomach relatively to the size of the patient, and I have never seen such complete atrophy of any organ constantly in use. The condition of the coats of the stomach was more like that of brown paper saturated in water than anything else to which I could compare it. The muscular and fibrcus coats were alike in a state of complete atrophy. A ligature placed around the œesophageal extremity cut through it like wet blottingpaper. I need scarcely say this was no post mortem softening. A portion was removed for microscopical examination, but unfortunately an accident prevented the intention from being carried out. However, I have no doubt that examination would have revealed the conditions presupposed.

REMARKS. - I have ventured to place this case before my professional brethren : first, because, as far as I know, it is one of rare occurrence ; secondly, as a reminder that absence of positive symptoms does not always indicate absence of structural disease ; thirdly, as a proof of the rapidity with which the abeyance of the primary function of nutrition will cause death. There are one or two peculiarities about this case to which I beg to draw attention. I. The case was eminently one of impaired nutrition ; yet there was no emaciation; on the contrary, there was abundance of adipose tissue over the body. 2. Although the process of fat-making went on, the process of sanguification, as far as red corpuscles were concerned, did not. If I may venture an explanation 